\title{
O que pode ser criticado nas críticas a $O$ Segundo Sexo*
}

\author{
Heci Regina Candiani**
}

\section{Resumo}

A recepção de $O$ Segundo Sexo, de Simone de Beauvoir, na Europa e nos Estados Unidos, principalmente a partir dos anos 1950 até os anos 1980, deu origem a muitas críticas. Nos círculos intelectuais, bem como nos estudos de gênero e feministas, tais críticas se consolidaram em interpretações dominantes do pensamento beauvoiriano. $\mathrm{Na}$ atualidade, novas leituras de suas obras, à luz de textos inéditos tornados públicos nos anos 1990, sugerem a necessidade de examinar o que tem sido dito e escrito sobre esse livro. Este artigo busca compreender as condições sociais e históricas de produção dessas críticas e refletir sobre como se tornaram dominantes por meio da investigação das relações de forças no interior dos círculos intelectuais principalmente na França, nos Estados Unidos e na Inglaterra - e do processo que Margaret Simons chamou de "o silenciamento de Simone de Beauvoir". O referencial teórico envolve a noção de campo intelectual, originária da obra de Pierre Bourdieu, mas que também é aplicada por pesquisadoras e pesquisadores de correntes sociológicas diversas a fim de refletir sobre as relações conflituosas que se estabelecem entre indivíduos e grupos nos círculos intelectuais. Por meio desse referencial, será possível colocar em questão diversas interpretações da obra beauvoiriana.

Palavras-chave: Simone De Beauvoir, Gênero, Silenciamento, Campo Intelectual, Trajetórias Intelectuais, Feminismo.

\footnotetext{
" Recebido em 30 de abril de 2019, aceito em 02 de outubro de 2019.

*** Doutora em Ciências Sociais pelo Instituto de Filosofia e Ciências Humanas da Universidade Estadual de Campinas, Campinas, SP, Brasil. heci@uol.com.br / http://orcid.org/0000-0002-2573-169X
} 
What Can Be Criticized in The Critiques of The Second Sex?

\begin{abstract}
The European and American reception of Simone de Beauvoir's The Second Sex, particularly from the 1950s to 1980s, gave rise to much criticism. In intellectual circles as well as in gender and feminist studies, this criticism became consolidated as the dominant interpretation of Beauvoir's thought. Today, new readings of her works in the light of previously unpublished texts by the author, released in the 1990s, suggest the need to examine what was said and written about this book. The purpose of this article is to understand the social and historical conditions of these critiques and consider how they became dominant, by investigating power relations within intellectual circles, especially in France and the United States, and the process Margaret Simons (1983) called "the silencing of Simone de Beauvoir". The theoretical framework involves the concept of intellectual field, which originated in Pierre Bourdieu's works but is also applied by researchers in different sociological currents, to think about conflicts among individuals and groups in intellectual circles. This theoretical framework will allow questioning several interpretations of Beauvoir's work.
\end{abstract}

Keywords: Simone De Beauvoir, Gender, Silencing, Intellectual Field, Intellectual Trajectories, Feminism. 


\section{Introdução}

"Em que medida o estudo O Segundo Sexo, de Simone de Beauvoir, ainda é relevante?", questiona a edição de $A \mathrm{New}$ Dawn for The Second Sex, de Karen Vintges (2017).

"Meu objetivo é mostrar a evolução das leituras de $O$ Segundo Sexo, para sugerir que [a obra] ainda merece ser considerada", afirma Ursula Fabijancic em seu artigo no volume 15 da revista Simone de Beauvoir Studies (Fabijancic, 1998-1999).

"Em que a leitura de $O$ Segundo Sexo lhe parece ainda pertinente para uma jovem dos dias atuais?", interroga Laura Fielding em um chat com Josyane Savigneau, jornalista do Le Monde, em 7 de março de 2011.

"Devemos ler Simone de Beauvoir?", foi o título que Nancy Bauer escolheu para seu artigo em um livro publicado em 2004 sobre o legado beauvoiriano. ${ }^{1}$

No momento em que a publicação de Le Deuxième Sexe (1949) completa 70 anos, uma pergunta, em suas muitas variações, insiste em nos interpelar: por que ler $O$ Segundo Sexo na atualidade? As respostas a essa pergunta podem ser muitas. Mas, considerando-se uma perspectiva que busca compreender $\mathrm{o}$ contexto de recepção dessa obra e as críticas que recebeu, talvez encontrar as respostas seja menos interessante do que investigar as raízes da indagação.

Ao nos perguntarmos "por que, na atualidade, ler" determinada obra com décadas de existência, implicitamente anunciamos que existem motivos para não a ler, para superá-la. Trata-se de uma pergunta, muitas vezes, retórica que, mais do que uma resposta, busca reivindicar o direito de recusa ao texto, e carrega a suposição de que o que está ali dito já foi suficientemente processado e criticado, a ponto de perder $o$

1 Esta é uma seleção, entre muitas citações possíveis, de perguntas afirmações semelhantes, que podem ser encontradas em artigos acadêmicos, periódicos literários, jornais e revistas de grande circulação, sites feministas, blogs, vídeos, tanto em língua francesa quanto inglesa ou portuguesa. As citações aparecem em versão já traduzida por mim. 
interesse na atualidade. E é justamente para refutar tais suposições que muitas estudiosas da obra e do pensamento de Simone de Beauvoir retornam a ela.

O que proponho neste artigo é discutir algumas críticas que, tendo se originado em contextos específicos, se consolidaram como interpretações hegemônicas e, assim, estão na base da suposição de que a leitura ou releitura de O Segundo Sexo, em especial, e da obra de Simone de Beauvoir como um todo precisa ser justificada. Pretendo sugerir que muitas críticas (feministas ou não) a $O$ Segundo Sexo têm origem em questões que transcendem o conteúdo $e$ a proposta da obra e são marcadas por cumplicidades e conflitos que se desenvolvem dentro dos interesses específicos de agentes dos campos intelectuais francês $e$ estadunidense. Nesse sentido, a proposta é pensar como, historicamente, texto e autora têm sido silenciados por questões que são externas ao próprio texto $e$ ao projeto intelectual de que resulta. Com essa discussão, espero mostrar que um dos motivos para lermos $O$ Segundo Sexo hoje pode ser a intenção de estabelecer uma nova leitura crítica do texto e uma relação renovada com sua autora.

\section{A noção de campo intelectual $e$ o contexto francês}

É em "Campo intelectual e projeto criador", publicado originalmente em 1966 na revista Les Temps Modernes (da qual Simone de Beauvoir era a editora responsável), que Pierre Bourdieu apresenta a noção de campo intelectual. Essa noção é derivada de uma teoria dos campos sociais, que Bourdieu começa a desenvolver no início daquela década. Para ele, uma sociedade pode ser compreendida como um conjunto de diferentes microcosmos sociais, relativamente autônomos entre si, com normas, lógicas, conflitos e interesses próprios. A esses microcosmos Bourdieu denominou "campos".

Cada campo é um sistema estruturado, com hierarquias, regras, uma série de disposições incorporadas de percepção $e$ ação (que Bourdieu denominou como habitus) e espaços de luta 
em torno da apropriação ou redefinição de um capital social específico. Esse capital se distribui de forma desigual entre os agentes do campo que, por meio de estratégias conservadoras ou subversivas, de cumplicidades e oposições, entram em um jogo de forças para assumir uma posição hegemônica no campo ou ascender em seu interior. No campo intelectual, a luta se dá em torno do capital cultural: saberes e conhecimentos reconhecidos por instituições, por meio de diplomas ou títulos e, com eles, a possibilidade de definir o que é legítimo em termos de produção de saber, de fazer valer ideias já operantes no campo ou de apresentar e tornar dominantes novas ideias que sejam reconhecidas como saber legítimo.

No momento em que Beauvoir escreve $O$ segundo sexo, meados do século XX no contexto europeu do pós-guerra, o campo intelectual francês tinha a filosofia como disciplina hegemônica na produção de saber e assistia à ascensão de agentes associados à corrente filosófica existencialista, mais especificamente ao existencialismo sartreano. Simone de Beauvoir era uma dessas agentes.

A presença de uma mulher em um campo cuja lógica é predominantemente masculina é, em si, já uma questão a ser analisada. Beauvoir era uma exceção, mas já havia conquistado sua posição no campo com uma trajetória de mais de 20 anos de intensa dedicação ao projeto de se tornar intelectual e escritora: em 1929, foi a pessoa mais jovem até então e uma das primeiras mulheres a obter uma agrégation em filosofia e, pouco depois, a primeira professora de filosofia em um liceu só de homens; em 1945, tornou-se a única mulher com poder de decidir questões editoriais em uma importante publicação da intelectualidade francesa desde o fim da guerra, a revista Les Temps Modernes (Bair, 1990). A questão de sua inserção no meio intelectual, entretanto, não era livre de conflitos, como ela relata na "Introdução" de O Segundo Sexo:

Agastou-me, por vezes, no curso de conversações abstratas, ouvir os homens dizerem a mim: "Você pensa assim porque 
é uma mulher". Mas eu sabia que minha única defesa era responder: "penso-o porque é verdadeiro", eliminando assim minha subjetividade. Não se tratava, em hipótese alguma, de replicar: "E você pensa o contrário porque é um homem", pois está subentendido que o fato de ser um homem não é uma singularidade [...] (Beauvoir, 2009 [1949]:16).

A frase "Você pensa assim porque é uma mulher" traduz uma lógica do campo intelectual em que Beauvoir estava inserida que tem diversos desdobramentos. Assim que O Segundo Sexo foi publicado, em 1949, as críticas à obra foram principalmente negativas. Ao propor que as reflexões sobre as mulheres $e$ a diferença sexual fossem realizadas pela filosofia, Simone de Beauvoir colocou em questão toda a pretensão de neutralidade e objetividade em que se baseava o pensamento humanista até então. Beauvoir expôs o fato de que as ideias dominantes no campo intelectual eram, então, falhas e não levavam ao ponto de crítica radical as implicações políticas, sociais e existenciais de um fato que ela prova no livro: as relações entre os sexos se constituem por desigualdades. Além disso, a mulher que era uma exceção no campo ousou expor e questionar as regras do campo, às quais deveria se submeter, com um obra que cumpria rigorosamente todas essas regras.

Pierre Bourdieu (2004) destaca que a estabilidade do campo intelectual depende também das questões que podem ser legitimamente apresentadas. Pode-se compreender que existe entre os agentes do campo um acordo tácito (parte do habitus) no campo a respeito de quais questões podem ser levantadas $e$ discutidas. Quando uma nova ideia desestabiliza esse tipo de acordo, essa subversão coloca em risco o reconhecimento do capital cultural do agente responsável por ela. A nova proposição será eficientemente combatida por uma reação dos agentes hegemônicos. Estabelece-se um debate de ideias e uma disputa de poder. Desse embate pode resultar uma nova configuração de forças ou o fortalecimento das forças hegemônicas. 
O caso de Beauvoir é exemplar de como, nesse embate, as ideias são muitas vezes secundárias. A resposta do campo a $O$ Segundo Sexo veio, em um primeiro momento, na forma de um ataque direto à autora. São já conhecidas as atitudes de François Mauriac e Albert Camus ao livro.

Beauvoir registra em A Força das Coisas como Camus a acusou, em tom de piada, de desonrar "o macho francês". Não foi o único macho a se ressentir:

Recebi epigramas, cartas, sátiras, molestações, exortações que me dirigiam, por exemplo "membros muito ativos do primeiro sexo". Insatisfeita, frígida, priápica, ninfomaníaca, lésbica, cem vezes abortada, fui tudo, até mãe clandestina. Ofereciam curar-me a frigidez, saciar meus apetites de gula, me prometiam revelações em termos grosseiros, mas em nome da verdade e da beleza, do bem, da santidade e até da poesia, indignamente devastadas por mim... Também Mauriac. Escreveu a um dos colaboradores de Les Temps Modernes: "Aprendi tudo sobre a vagina da vossa patroa" (Beauvoir, 2010:16).

A reação de Mauriac, um dos principais nomes da direita católica em meados do século XX, entretanto, pode ser entendida como muito mais do que anedótica: agiu como um guardiáo do status quo do campo intelectual, das ideias conservadoras e de forças e processos internos ao campo. Imediatamente, ele iniciou um backlash contra Beauvoir, escrevendo contra ela artigos de ataque explícito à sua sexualidade, à sua personalidade $e$ ao existencialismo que ela representava. Evocando a lógica da cumplicidade entre os demais intelectuais do campo, convocou-os a escreverem contra Beauvoir (Chaperon, 1999). Toril Moi (2008) afirma que a suposta pretensão de Beauvoir a uma posição como mulher intelectual foi o maior problema. Mas, mais do que isso, a reação parece ter sido provocada pelo fato de Beauvoir, a partir de sua posição marginal no campo, propor ideias que o desestabilizavam. 
O Segundo Sexo se tornou, assim, o estopim de disputas políticas que, para além da polêmica, colocaram a autora em uma posição de alvo fácil de críticas. A convocação de Mauriac também foi um sinal de que o livro deveria ser criticado, atacado fortemente, desqualificado. Em um momento em que o feminismo tinha praticamente nenhuma influência no campo intelectual, as interpretações que esses intelectuais apresentavam eram menos importantes do que a postura de ataque. Ao incomodarem um dos grupos mais influentes do campo, o dos intelectuais homens conservadores e católicos, obra e autora tornaram-se imediatamente alvos legitimados de críticas.

E elas vieram em abundância na forma de ataques pessoais: frígida, imoral, emotiva nas escolhas políticas, não maternal, dessexualizada, "ingênua e epistemologicamente impostora", "boa aluna, mas não intelectual". A lista é longa e foi mapeada por Toril Moi (2008). Na maioria das vezes, os termos usados concentravam-se em colocar Beauvoir (e eventualmente outras mulheres) em seu lugar, ou seja, sob o domínio da reprodução da espécie e da subordinação intelectual e sexual aos homens.

Nesse sentido, o ataque à visão beauvoiriana de maternidade foi fundamental. $\mathrm{O}$ termo não maternal não é escolhido ao acaso e sim por marcar um aspecto da experiência vivida das mulheres que está necessariamente ligado à biologia. Evocar a questão da biologia, da natureza e do "instinto" maternal era, como estratégia de conservação das relações de forças no campo, a postura mais tradicional. Afinal, grande parte da discussão de Beauvoir em $O$ Segundo Sexo gira em torno de como a associação entre "feminino", "biologia" e "natureza" é o elemento-chave de toda a produção social da condição da mulher como Outro.

O contexto da desqualificação de Simone de Beauvoir como mulher, como intelectual é fundamental, portanto, para deslegitimar o livro no campo intelectual. No estudo sobre os "anos Beauvoir", Chaperon (2000) mostra como, entre 1947 e 1955, principalmente, a Guerra Fria domina o ambiente político e intelectual interno. A polarização política externa entre União 
Soviética e Estados Unidos se reflete na sociedade francesa e, em especial, no campo intelectual francês. Estabelece-se uma polarização entre esquerda (marcadamente comunista) e direita (especialmente católica). $\mathrm{O}$ existencialismo se insere no campo como um elemento incômodo para ambos os lados por não se alinhar em hipótese alguma com a direita e por não se alinhar plenamente com a esquerda.

O movimento das mulheres, que ainda pouco usava a palavra feminista, havia, em parte, abraçado os argumentos natalistas (que ecoavam na direita e na esquerda) quanto à importância, para a economia e a política do país, de que as mulheres deixassem seus empregos assumidos durante a guerra $e$ retornassem a seus lares, assumindo seu "verdadeiro" papel que era gerar e educar as crianças.

O discurso de valorização da maternidade como "instinto", função e realização da mulher estava nas mídias, campanhas governamentais e no movimento de mulheres. As representantes da direita católica associavam esse argumento ao discurso de preservação da família. E as da esquerda comunista, que produziram as críticas mais veementes contra o livro de Beauvoir, se alinhavam ao natalismo, que também era forte na União Soviética (Germain, 2013), porque essa estratégia política a aproximava do novo eleitorado, as mulheres. A esquerda disseminava também a visão de que a luta das mulheres não seria necessária em um sistema socialista. Sendo assim, a inserção do debate sobre liberdade das mulheres, liberação sexual e direitos reprodutivos, proposto por Beauvoir, era inadequada para ambos os lados: para a direita, o livro de Beauvoir era "imoral" por atentar contra dois pilares do conservadorismo, a família patriarcal e a religião; para a esquerda, era "imoral" em outros termos: individualista, burguês e planejado para enfraquecer a luta de classes.

A leitura das ideias beauvoirianas sobre maternidade era, assim, sustentada nas condicionantes sociais de gênero que interessavam aos grupos políticos dentro $e$ fora do microcosmo intelectual francês do pós-guerra. Relativamente autônomo em 
relação aos demais campos, mas também influenciado por eles, o campo intelectual tinha sua própria versão dessas condicionantes. Em certa medida, as críticas recebidas por Beauvoir que reverberavam essas condicionantes são também denunciadas pela autora em seu texto ("você pensa isso porque é uma mulher").

Essas reações evidenciam como, ao se contrapor diretamente à transformação da figura materna e da função da maternidade pelo Estado francês em elemento central de uma política de controle dos corpos e da população no contexto do pós-guerra, $O$ Segundo Sexo desestabilizava não apenas o campo intelectual, mas também o político. E mostra também como a autonomia do campo intelectual em relação ao político, naquele momento histórico, era pequena. Essa reação ao debate beauvoiriano sobre a maternidade, determinada por questões específicas daquele contexto sócio-político, não foi ainda superada. Ainda hoje, dissemina-se a crítica de que o livro tem uma visão negativa da maternidade, e que isso está associado à visão negativa pessoal da autora sobre a experiência de ser mãe, consequência de uma disposição pessoal de Beauvoir, que estaria ligada à sua opção de não ter crianças ou à sua relação complexa com a própria mãe (entre outras "explicações").

$\mathrm{O}$ embate de forças do campo intelectual francês que teve como gatilho a publicação de $O$ Segundo Sexo não se esgota nos anos 1950. Durante a segunda metade da década de 1940 e a década de 1950, o existencialismo sartreano, de orientação fenomenológica, se estabeleceu como corrente de pensamento hegemônica e atingiu seu auge (Bourdieu, 2004), trazendo novos acordos e lógicas para o campo. Nesse momento, principalmente no contexto das universidades, a filosofia é dominante e há uma reação à pretensão das ciências sociais de produzirem um conhecimento com rigor metodológico.

A década seguinte verá uma transformação nessa ordem. Bourdieu (2004) relata que, nos anos 1960, o estruturalismo se consolida como corrente legítima no interior do campo, ameaçando a hegemonia existencialista e, também, a da própria filosofia. As ciências sociais, antes compreendidas como tentativas 
malsucedidas de fazer filosofia, ganham com a perspectiva estruturalista, em que linguística e antropologia têm maior força, um prestígio inédito, questionando a perspectiva humanista, a valorização da experiência vivida e o conceito de liberdade (três pontos fundamentais do existencialismo). Quase concomitantemente, o campo intelectual vê emergir também a corrente pós-estruturalista, que recusa tanto premissas estruturalistas quanto existencialistas, e se fortalece a partir de 1968.

A nova configuração do campo nos anos 1960 e 1970 é marcada, então, pela ascensão de propostas teóricas que rechaçam o existencialismo. Estruturalismo e pós-estruturalismo, ainda que em disputa entre si, também têm o interesse comum de desestabilizar o domínio do grupo que tem em Sartre a figura central. A complexidade das lutas se intensifica, porque o debate teórico que era praticamente ausente nos anos 1940 e 1950 se torna muito mais presente e passa a envolver diretamente o feminismo influenciado pelo pós-estruturalismo, com obras de pensadoras importantes como Hélène Cixous, Julia Kristeva, Antoinette Fouque, Luce Irigaray e Monique Wittig. ${ }^{2}$ Baseadas no modelo teórico pós-estruturalista, que coloca a estrutura da linguagem e a desconstrução do sujeito como um todo coerente, as chamadas "feministas da diferença" reafirmam a diferença biológica da fêmea humana como essencial e o termo "mulher", de acordo com as formulações de Kaufmann (1998:122), como uma "metáfora para o inconsciente da cultura, tudo o que foi deixado de lado pela economia libidinal masculina". Para elas, a visão beauvoiriana de um mundo além do discurso é ultrapassada e masculinista por não enfatizar a mulher como diferente $e$ o texto de Beauvoir peca por sua atenção à mulher "como ela existe na

2 Embora haja diferenças de perspectivas e proposições teóricas entre elas e haja quem questione a condição dessas pensadoras como feministas, elas exerciam uma influência importante no feminismo francês e são frequentemente agrupadas em torno do conceito de écriture féminine, ligando as práticas intelectuais, culturais e artísticas à problemática da diferença sexual não como construção, mas como uma essência feminina. 
ordem social" e por "presunção de um mundo fora do texto": Beauvoir "ainda consegue falar a respeito da realidade e da experiência vivida sem usar aspas" (Kaufmann, 1998:122), o que é entendido como ultrapassado e falocêntrico.

Apesar disso, novamente o debate será conduzido a partir da questão da natureza. Essas feministas criticam Beauvoir por enxergar em seu texto a mesma hostilidade contra a maternidade que os homens dos anos 1950 atacavam, afirmando que o texto beauvoiriano é misógino. Nesse momento, o termo assume uma força estratégica muito relevante porque Beauvoir já era considerada uma referência feminista e o feminismo está em ascensão tanto no campo político, pela militância, como no campo intelectual pela produção teórica.

Nesse contexto, dois nomes se destacam: Beauvoir $e$ Fouque, representantes de duas das muitas vertentes do feminismo na França dos anos 1970. Como especifiquei em outro texto (Candiani, 2018), Beauvoir representava um feminismo igualitarista para o qual a importância da biologia nas desigualdades sociais entre homens e mulheres é pequena em termos concretos, mas importante ao possibilitar que diferenças biológicas sejam utilizadas para justificar aspectos determinantes da opressão das mulheres. Fouque representava um feminismo essencialista em que a biologia é determinante para o destino da mulher $e$ a igualdade não é um ideal a ser alcançado, o que importa é a valorização das mulheres em suas diferenças. Esse embate não é estranho ao feminismo contemporâneo, que apresenta defesas de ambas as premissas. No contexto francês, entretanto, o grupo Psych et Po, marcado pelo essencialismo de Fouque, acabou por se tornar dominante, colaborando para o fortalecimento do pós-estruturalismo e da psicanálise como correntes hegemônicas, em oposição ao existencialismo, que encontra então seu declínio. Nesse processo, a interpretação de Beauvoir como ultrapassada e misógina se cristalizou e suas contribuições para o feminismo passam a ser lidas como apenas reformulações da visão sartreana de sujeito. 
Assim, as críticas historicamente consolidadas ao debate proposto por Beauvoir em $O$ Segundo Sexo a respeito da maternidade estão sujeitas a uma reavaliação crítica tendo como base a compreensão de que muita leituras e interpretações nascem de um contexto de luta pelo domínio do capital cultural francês. O que pode ser criticado nas críticas a $O$ Segundo Sexo, nesse contexto, é o modo como as ideias de Beauvoir são silenciadas sob um manto de embate de forças e interesses internos ao campo, sejam eles os de garantir uma hegemonia da direita católica ou de derrubar a hegemonia existencialista, em um momento posterior.

Essa é a lógica do campo, as críticas são mesmo estabelecidas a partir de interesses específicos de grupos interessados em dominar o capital cultural. Mas o que é importante ter em mente é que, a partir da perspectiva de como esse processo influencia as críticas, podemos retomá-las e também criticá-las como um produto histórico e social cuja legitimidade, mesmo no campo intelectual, não precisa ser reafirmada. Uma dificuldade nesse processo, entretanto, é que ele também desestabiliza a visão objetiva e positiva de construção de conhecimento na qual se sustenta o campo intelectual. As críticas se consolidam porque são compreendidas como objetivas $e$ neutras; a observação da dinâmica do campo intelectual coloca essa compreensão em questão.

\section{O campo intelectual estadunidense}

Moi (1990) e Cyfer (2015) destacam que a importância de Beauvoir como pensadora passa a ser subestimada, dentro e fora dos feminismos, a partir da influência do estruturalismo e do pósestruturalismo, correntes cujas teorias migram rapidamente do contexto francês para o estadunidense junto com a migração temporária de intelectuais franceses importantes como Claude Lévi-Strauss e Michel Foucault para o país. A partir dos anos 1960 e, principalmente, na década de 1980, o estudo do pensamento beauvoiriano migra também quase que completamente para os 
Estados Unidos. Ali, Beauvoir encontra uma recepção completamente diferente. Ela era uma estrangeira com alinhamento ideológico à esquerda no espectro político, o que em si já significava que sua posição no campo intelectual estadunidense tenderia a se tornar marginal ${ }^{3}$ no contexto da Guerra Fria. Ainda mais porque, na obra, Beauvoir dialoga, em muitos momentos na forma de uma crítica ácida, com a cultura estadunidense. Ao mesmo tempo, a possibilidade de que suas ideias desestabilizassem o campo, como aconteceu na França, era remota. Entretanto, é interessante notar que as críticas produzidas nesse outro contexto se tornam relevantes $e$ se consolidam por outros caminhos: a hegemonia estadunidense na produção $e$ divulgação de conhecimento.

A história da recepção de O Segundo Sexo nos Estados Unidos se inicia nos anos 1950. O texto foi traduzido para o inglês em 1953. A edição estadunidense, que circulou em todos os países de língua inglesa a partir de então, era uma condensação do original. A recepção inicial desse texto é raramente discutida porque, em grande parte, é principalmente a partir dos anos 1970 que o livro passa a ser estudado como referência para a teoria feminista nas universidades e influencia nomes importantes do feminismo estadunidense, como Betty Friedan e Kate Millet. Essas e outras autoras apropriam-se muito do pensamento de Beauvoir sem lhe conceder créditos (Pilardi, 1995). Em um segundo momento, já citada e reconhecida, Beauvoir irá influenciar Gloria Steinem, bell hooks e Shulamith Firestone, entre outras.

O espaço que separa 1953 de 1970, entretanto, tem um profundo interesse para a compreensão de como $O$ Segundo Sexo é recebido nos Estados Unidos e de como algumas críticas são gestadas. O quebra-cabeças para compreender o lugar que o texto beauvoiriano irá ocupar no contexto estadunidense começa a se

3 Não porque Beauvoir fosse desconhecida no campo intelectual estadunidense: sua viagem ao país, em 1947, durante a qual realizou conferências em muitas universidades, principalmente as que eram voltadas para a educação de mulheres, já tornara seu nome razoavelmente conhecido. 
formar a partir desses fatores: o livro foi traduzido pela editora Knopf com a intenção de vendê-lo como versão feminina do relatório de Alfred Kinsey sobre a sexualidade masculina, publicado em 1948, e que se tornou uma publicação bastante popular. A obra, portanto, não tinha como público-alvo agentes do campo intelectual. O trabalho de simplificação, cortes, supressão de trechos e conceitos filosóficos atendia ao objetivo de buscar uma audiência mais ampla e popular.

A investigação sócio-histórica do caso demonstra que a tradução de 1953 teve diversos fatores complicadores: a falta de conhecimento filosófico do tradutor, as solicitações do editor para cortar e simplificar o texto, a intenção da editora de enfatizar o caráter científico do livro e a falta de cooperação de Beauvoir (Bogic, 2009:ii). ${ }^{4}$

O livro, entretanto, tem também um interesse intelectual por se aproximar, ou ter sido aproximado a partir das escolhas editoriais, da sexologia e das ciências sociais, em especial a antropologia.

As leituras do texto nos anos 1950, no campo intelectual, estão condicionadas por uma série de fatores. Primeiro, o fato de que o conflito do campo intelectual francês teve pouca influência no campo intelectual estadunidense (Germain, 2013), especialmente porque as correntes dominantes na França, catolicismo e comunismo, tinham pouca voz entre a intelectualidade dos Estados Unidos. Além disso, nesse momento, a autonomia relativa do campo intelectual estava sob a vigilância marcartista e as forças da esquerda estavam enfraquecidas ou recuadas. Mais do que isso, nesse período, as pautas feministas apresentadas por Beauvoir em $O$ Segundo Sexo, em especial a

${ }^{4}$ No original: "The sociohistorical investigation of the case study demonstrates that the 1953 translation was complicated by several factors: the translator's lack of philosophical knowledge, the editor's demands to cut and simplify the text, the publisher's intention to emphasize the book's scientific cachet, and Beauvoir's lack of cooperation." 
questão da contracepção e da liberação sexual, tinham pouca relevância nos meios intelectuais estadunidenses: as mulheres, em especial a elite econômica e intelectual, já tinha seu direito à contracepção garantido. Ao contrário da França, os Estados Unidos também já haviam reconhecido as vantagens da presença das mulheres no mercado de trabalho. Para Germain, entretanto, outros três pontos impediram uma recepção simpática à obra:

\begin{abstract}
Primeiro, ao contrário de Beauvoir, autores estadunidenses acreditavam que a sociedade "moderna", com o que eles queriam dizer os Estados Unidos, deveria combinar a emancipação feminina, especialmente no trabalho, com a preservação da "feminilidade". Segundo, a visão de Beauvoir de que "não se nasce mulher" conflitava com as ideias biologicamente deterministas que eram populares entre cientistas estadunidenses nos anos 1950. Em terceiro lugar, e o que é mais importante, críticos estadunidenses foram incensados pelo que tomaram como uma difamação da maternidade por Beauvoir (Germain, 2013:1041). ${ }^{5}$
\end{abstract}

Germain lista uma série de críticas a $O$ Segundo Sexo produzida nos anos 1950, inclusive destacando a resenha de Margaret Mead, importante agente do campo intelectual na época, e o prefácio escrito por H. M. Parshley, o tradutor da obra para o inglês. Nessa pesquisa, sobressaem principalmente as críticas às visões beauvoirianas sobre o trabalho feminino e a maternidade.

Em relação ao tema do trabalho, de acordo com Germain (2013), os argumentos beauvoirianos foram recebidos com incômodo pelo campo intelectual. Beauvoir tem uma visão do trabalho como um caminho para a independência da mulher $e$

${ }^{5}$ No original: "First, unlike de Beauvoir, American writers believed that 'modern' society, by which they meant America, should combine female emancipation, especially at work, with the preservation of 'femininity'. Secondly, de Beauvoir's view that 'woman is made not born' clashed with biologically determinist ideas popular among American social scientists by the 1950s. Thirdly, and most importantly, American critics were incensed by what they took to be de Beauvoir's denigration of motherhood". 
como via de acesso ao projetos criativos que ela associa com a transcendência. Entretanto, Beauvoir constrói parte desse discurso criticando justamente o lugar das mulheres estadunidenses no mercado de trabalho, o modo como essa inserção se dá. Beauvoir está atenta ao fato de que desenvolver uma carreira não era uma alternativa para as mulheres, mas era um encargo a mais que não as isentava das obrigações familiares e domésticas. $\mathrm{O}$ debate no campo intelectual se dava no sentido de como as mulheres podiam conciliar maternidade, casamento e carreira. Não era o tipo de independência que Beauvoir tinha em mente e seus comentários foram lidos como críticas implícitas e explícitas à cultura estadunidense.

A crítica à visão da autora da maternidade retorna, em outro contexto social e político. Também nesse tópico, segundo Germain (2013), o que prevalece no campo intelectual é a ideia de que a maternidade é função biológica da mulher e deveria ser reconciliada com a feminilidade. Maternidade e feminilidade eram compreendidas como fatores da estabilidade social e preservação da família. Os valores familiares eram constantemente reafirmados. Assim, as críticas à visão beauvoiriana de maternidade no campo intelectual estadunidense nos anos 1950 estavam profundamente arraigadas em uma compreensão de sociedade calcada em valores tradicionais e bastante contrários ao que Beauvoir defendia no livro: o determinismo biológico e a família como núcleo social essencial.

Ainda que as bases das críticas produzidas então possam parecer semelhantes às críticas conservadoras e mesmo comunistas francesas, há uma diferença. O campo intelectual estadunidense não busca necessariamente desacreditar Beauvoir com base em suas escolhas e vivências pessoais. Na verdade, nesse primeiro momento, as críticas ocorrem mais como um debate de ideias que busca realizar uma defesa da visão de sociedade hegemônica que é marcada por termos como "crescimento econômico", "modernidade", "progresso", embora as bases sejam a de manutenção do status quo. 
Isso se altera entre os anos 1960 e 1980:

Desde os anos 1960, o pensamento feminista sobre a maternidade tem sido descrito como "uma peça em três atos". Como especifica Emily Jeremiah, o primeiro ato, ao qual Beauvoir é amplamente associada, envolve o "repúdio" à maternidade. O segundo, que começou em meados dos anos 1970, tentou "resgatar" ou reivindicar a maternidade, e o terceiro ainda está sendo representado (Kirkpatrick, 2014:275). ${ }^{6}$

Os anos 1970 são, então, uma tentativa de "resgatar" o valor da maternidade $e$ as críticas a Beauvoir partem especialmente das feministas, muitas delas influenciadas pelo pósestruturalismo francês. Beauvoir passa a ser mais frequentemente discutida no campo intelectual, nos grupos feministas que, embora se inspirem em sua figura, seu estilo de vida $e$ seus posicionamentos políticos, acusam $O$ Segundo Sexo de ser universalista e misógino. Também nesse momento, há uma grande resistência ao modo como Beauvoir questiona a maternidade como função essencial, natural, da mulher.

Curiosamente, nos anos 1970 e 1980, nos Estados Unidos, é justamente essa a crítica que as mulheres farão sobre a visão beauvoiriana de maternidade: essencialista. Embora algumas feministas compartilhassem das ideias beauvoirianas de que a maternidade era um meio de manter a condição da mulher como inferior social e economicamente, a maioria afirmava que essa visão era universalista e essencializava as mulheres. Curiosos são também os termos utilizados para qualificar a descrição beauvoiriana da maternidade: horrível, medo, ultrapassada, dramática, negativa. Mas o quanto desses termos referem-se

${ }^{6}$ No original: "Since the 1960s, feminist thinking on maternity has been described as 'a drama in three acts'. 1 As Emily Jeremiah sets it out, the first actwith which Beauvoir is widely associated-involves a 'repudiation' of motherhood. The second, which began in the mid-1970s, attempted to 'recuperate' or reclaim maternity, and the third is still playing ouf'. 
menos à descrição de Beauvoir e mais ao fato de ela ousar colocar no centro do debate a experiência materna, até então romantizada e objetificada pelos homens, dominantes no campo intelectual?

Quando decide iniciar seu capítulo sobre a maternidade em $O$ Segundo Sexo com uma discussão sobre direitos reprodutivos e aborto, Beauvoir certamente queria causar polêmica e incomodar as mentes mais conservadoras. Embora a leitura deixe claro que esse e outros recursos textuais são empregados a fim de eliminar qualquer perspectiva idealizada da gestação e do parto, Beauvoir declarou várias vezes que reconhecia como legítima a opção consciente das mulheres pela maternidade, mas considerava essencial que elas não se identificassem exclusivamente com o papel de mães. Entre as pensadoras do campo intelectual estadunidense dos anos 1970 e 1980 quem parece ter sido capaz de melhor compreender a visão de Beauvoir foi Judith Butler:

(...) a dificuldade generalizada em aceitar a maternidade, por exemplo, como uma realidade institucional e não instintual expressa a mesma interação entre coerção $e$ liberdade. A visão de Simone de Beauvoir do instinto maternal como uma ficção cultural frequentemente se depara com o argumento de que um desejo sentido de maneira tão comum e irrefutável deve, exatamente por esse motivo, ser considerado orgânico e universal (Butler, 1986:42). ${ }^{7}$

Nesse trecho, Butler parece ter encontrado a chave de crítica às críticas recebidas por Beauvoir e que pode ser aplicada tanto ao contexto estadunidense quanto ao francês: a dificuldade em reconhecer algo que Beauvoir argumenta ao longo de todo o livro: o que é justificado como natural é, majoritariamente, institucional.

7 No original: "...the widespread difficulty in accepting motherhood, for instance, as an institutional rather than an instinctual reality expresses this same interplay of constraint and freedom. Simone de Beauvoir's view of the maternal instinct as a cultural fiction often meets with the argument that a desire so commonly and so compellingly felt ought for that very reason to be considered organic and universal'. 


\section{Conclusão}

Tanto para o pensamento tradicional como para as teorias feministas, foi difícil compreender as especificidades do pensamento $e$ do método beauvoirianos $e$, diante das dificuldades, muitas vezes as interpretações sexistas, os lugarescomuns $e$ as hostilidades políticas foram cristalizadas como críticas legítimas à sua teoria. A recorrência das interpretações negativas sobre o debate que Beauvoir propõe em torno da maternidade sugere que havia também um padrão nos campos intelectuais francês e estadunidense a respeito do que poderia ou deveria ser criticado em $O$ Segundo Sexo. Assim como define que ideias merecem ser legitimadas, o campo intelectual delineia limites e reforça a resistência a determinadas ideias que não serão aceitas. Acordos estabelecem-se também nesse sentido.

Muitas feministas, como Élisabeth Badinter, Silvia Federici e Nancy Fraser, para citar apenas algumas, já demonstraram ao longo das últimas décadas como a maternidade e o trabalho de reprodução social da mulher são essenciais para o capitalismo. Uma releitura do tema da maternidade em Simone de Beauvoir pode nos indicar em que medida as críticas hoje cristalizadas contra seu texto, especificamente em relação a esse tema, podem ser repensadas à luz de novas teorias. Também é interessante notar que, se o mesmo tema ressurge em épocas e lugares diferentes, há uma questão a ser interpelada. Muito já foi escrito sobre a visão de maternidade de Beauvoir e essa interpelação demandaria um profundo trabalho de pesquisa, que poderia se beneficiar de uma abordagem a partir do referencial do campo intelectual.

$\mathrm{O}$ que procurei mostrar neste texto foi que muitas das críticas destacadas acabaram por promover um processo de silenciamento de Simone de Beauvoir, dentro e fora das teorias feministas. A hipótese do silenciamento de Beauvoir é inicialmente levantada por Margaret Simons em seu artigo "The Silencing of Simone de Beauvoir: Guess What is Missing from The Second Sex" (1983). Nele, Simons aponta detalhadamente a omissão de 
conceitos, referências, personagens históricas e argumentos de Beauvoir no momento da tradução de Le deuxième sexe para o inglês. A qualidade duvidosa da tradução, os objetivos editoriais e o contexto político estadunidense em que esse trabalho foi realizado apresentavam todas as condições para sustentar esse processo de omissão e supressão de ideias como condizente com os interesses não apenas do campo intelectual como também dos campos político e econômico nos Estados Unidos. Pelo monopólio dos direitos da obra em língua inglesa pela editora estadunidense, em certa medida esses interesses são exportados para todos os demais países em que o inglês era a língua dominante, como Canadá, as nações do Reino Unido, Índia etc. A hegemonia da língua inglesa também na produção acadêmica na área de estudos feministas e de gênero, que acaba por privilegiar a publicação de análises e pesquisas produzidas nessa língua e nesses países, também tem um papel importante em consolidar críticas que são produto de seus contextos sociais e políticos.

A análise apresentada aqui, que coloca Simone de Beauvoir como agente do campo intelectual a partir da qual são observados os movimentos e as disputas internas desse microcosmo social não tem como objetivo sugerir que Beauvoir era uma figura central nesse universo. Ao contrário. A ideia aqui é justamente observar como o campo pode ser observado a partir de um ponto de vista ambíguo, ao mesmo tempo central e marginal. No caso francês, central porque Beauvoir integrou um grupo dominante no interior do campo intelectual; marginal porque, ao mesmo tempo, no interior desse grupo, ela estava colocada à margem por ser mulher, escrever sobre as mulheres e colocar em questão a supremacia masculina que era a lógica dominante no campo. No caso estadunidense, Beauvoir era essencialmente uma agente estrangeira, marginal em função da língua, das ideias, e sobre cuja obra esse campo não hesitou em exercer uma apropriação claramente interessada, omitindo do texto tudo que não lhe convinha. $\mathrm{E}$, nesse sentido, há também uma ambiguidade, porque essa apropriação foi o que permitiu transformar Beauvoir e a 
versão de seu texto em inglês em uma obra de referência (ou seja, central) no campo (marginal) dos estudos de gênero e feministas.

Ao analisar esses campos intelectuais a partir de Simone de Beauvoir, pode-se portanto, ter uma visão mais complexa dos processos intelectuais. A dinâmica de um campo intelectual é complexa e sua lógica não é estática, os ajustes, os movimentos, as cumplicidades e oposições se constroem $e$ reconstroem o tempo todo, as ambiguidades e paradoxos são constantes. Especificamente no caso de $O$ Segundo Sexo, essa observação nos permite perceber que as críticas ao texto podem ser criticadas como produto de interesses muito localizados no tempo e no espaço, em interesses políticos e intelectuais específicos e pontuais, em lógicas e regras que se transformam. Nesse sentido, reproduzirmos na atualidade críticas antigas ao texto é também reproduzir não apenas práticas de silenciamento já instituídas como, ao mesmo tempo, recorrer ao silenciamento como estratégia. Na atualidade, esse silenciamento se produziria a partir de uma recusa em verificar que pontos e que críticas podem ser destacados no texto a partir de uma leitura que leve a obra em consideração tanto como um produto de seu tempo quanto como um texto capaz de transcendê-lo e trazer elementos que ainda não foram discutidos e que ainda nos interpelam e correspondem a questões contemporâneas.

Podemos criticar as críticas a $O$ Segundo Sexo produzidas ao longo das sete décadas da existência do livro como produtos de um ocultamento e de uma série de julgamentos que eram, em si, exatamente aquilo que acusavam o livro de ser: ultrapassados, misóginos, universalistas e masculinistas. Sobretudo, podemos criticar nessas críticas o fato de não serem consideradas como produtos de contextos específicos.

Assim, um dos motivos para "ler O Segundo Sexo hoje" pode ser simplesmente ir além de um véu que foi colocado em torno do livro e renovar nossa relação com a autora. Em abril de 1986, quando Simone de Beauvoir morreu, Susan Sontag declarou a um jornal estadunidense que considerava $O$ Segundo Sexo "um grande acontecimento na história da consciência, além 
de um livro libertador para todas as mulheres" (Meisler, 1986). Pensar o livro como um acontecimento para a consciência contemporânea é também pensar que as críticas que ocultam suas ideias foram uma tentativa de refrear a consciência, assim como seria hoje deixar de questioná-las.

\section{Referências bibliográficas}

BAIR, Deirdre. Simone de Beauvoir. A Biography. New York, Summit, Books, 1990.

BAUER, Nancy. Must We Read Simone de Beauvoir? In: Grosholz, Emily (ed.). The Legacy of Simone de Beauvoir. Oxford, Clarendon Press, 2004, pp.115-135.

BEAUVOIR, Simone de. A força das coisas. Rio de Janeiro, Nova Fronteira, 1999.

Beauvorr, Simone de. Cahiers de jeunesse. Paris, Gallimard, 2008.

BEAUVOIR, Simone de. O Segundo sexo. Rio de Janeiro, Nova Fronteira, 2009.

BogIC, Anna. Rehabilitating Howard M. Parshley: A Socio-historical Study of the English Translation of Beauvoir's Le deuxième sexe, with Latour and Bourdieu. Thesis for the MA degree in Translation. Faculty of Arts, University of Ottawa, Canada, 2009 [https://goo.gl/HnlsyD - acesso em: 15 maio 2015].

BogIC, Anna. Uncovering the Hidden Actors with the Help of Latour: The "Making" of The Second Sex. MonTI - Monografías de Traducción e Interpretación, n. 2, 2010, pp.173-192.

BOURDIEU, Pierre. Campo intelectual e projeto criador. In: PouILLON, J. (org.). Problemas do estruturalismo. Rio de Janeiro, Zahar, 1968, pp.105-145.

BouRdieu, Pierre. Coisas ditas. São Paulo, Brasiliense, 2004. [1987]

BouRdiEU, Pierre. O poder simbólico. Rio de Janeiro, Bertrand Brasil, 2010. [1989]

ButLER, Judith. Sex and Gender in Simone de Beauvoir's Second Sex. Yale French Studies, n. 72, 1986, pp.35-49. 
ChAPERON, Sylvie. Auê sobre O Segundo Sexo. cadernos pagu (12), Campinas-SP, Núcleo de Estudos de Gênero-Pagu/Unicamp, 1999, pp.37-53.

ChAPERON, Sylvie. Les Années Beauvoir (1945-1970). Paris, Fayard, 2000.

CYFER, Ingrid. Afinal, o que é uma mulher? Simone de Beauvoir e "a questão do sujeito" na teoria crítica feminista. Lua Nova, n. 94, São Paulo, 2015, pp.41-77.

FABIJANCIC, Ursula. Le Deuxième Sexe 1949-1999: our continuing dialogue with Simone de Beauvoir. Simone de Beauvoir Studies, vol. 15, 1998-1999.

Germain, Rosie. Reading The Second Sex in 1950s America. The Historical Journal, n. 56/4, 2013, pp.1041-1062.

LE MONDE. Beauvoir restera comme l'image d'une femme qui a voulu $\begin{array}{lllll}\text { penser sa } & \text { liberté, } & 7 & \text { mars } & 2011\end{array}$ [https://www.lemonde.fr/societe/chat/2011/03/07/feminisme-quenous-a-legue-simone-de-beauvoir_1489783_3224.html - acesso em: 28 abr. 2019].

KaUfmANN, Dorothy. Simone de Beauvoir: questions of difference and generation. Yale French Studies, n. 72, 1986, pp.121-131.

KIRKPATRICK, Kate. Past her Prime? Simone de Beauvoir on Motherhood and Old Age. Sophia, 53 (2), 2014, pp.275-287.

KRUKS, Sonia. Simone de Beauvoir: Teaching Sartre About Freedom. In: ArONSON, Ronald; VAN DEN Hoven, Adrian (ed.). Sartre Alive. Detroit, Wayne State University Press, 1991, pp.285-300.

KRUKS, Sonia. Beauvoir's Time/Our Time: The Renaissance in Simone de Beauvoir Studies. Feminist Studies, 31(2), 2005, pp.286-309.

MEISLER, Stanley. De Beauvoir, writer and feminist, dies. Los Angeles Times, April 15, 1986 [https://www.latimes.com/archives/la-xpm1986-04-15-mn-4814-story.html - acesso em: 18 abr. 2019].

MoI, Toril. Feminist Theory and Simone de Beauvoir. Oxford, Blackwell, 1990. 
PILARDI, Jo-Ann. Feminists read 'The Second Sex. In: SiMONS, Margaret A. (ed.). Feminist Interpretations of Simone de Beauvoir. University Park, PA, The Pennsylvania University Press, 1995, pp.29-43.

SimONS, Margaret. Beauvoir and the Second Sex: Feminism, Race, and the Origins of Existentialism. New York, Rowman \& Littlefield, 1999.

SIMONS, Margaret. Confronting an impasse: reflections on the past and future of Beauvoir scholarship. Hypatia, vol. 25, n. 4, Fall, 2010, pp.909-926.

SIMONS, Margaret. The silencing of Simone de Beauvoir: guess what's missing from "The Second Sex". Women's Studies International Forum, vol. 6, 1983, pp.559-64.

VINTGES, Karen. The Second Sex and Philosophy. In: SimONS, Margaret A. (ed.). Feminist Interpretations of Simone de Beauvoir. University Park, PA, The Pennsylvania University Press, 1995, pp.45-58.

VinTGES, Karen. A New Dawn for the Second Sex: Women's Freedom Practices in World Perspective. Amsterdam University Press, 2017.

ZERILLI, L. M. G. A process without a subject: Simone de Beauvoir and Julia Kristeva on maternity. Signs, 18(1), 1992, pp.111-135. 